\title{
Food Markets from a Local Dimension -La Boqueria (Barcelona, Spain)
}

\begin{abstract}
:
Food markets build communities for people, that is, they generate footfall and bring neighborhoods to life. Consequently, they become valuable tourist resources. The success of these tourist resources depends on the host community support; depends on the positive and favorable opinion of residents. Therefore, the aim of this study is to test different variables (resident place image, community attachment, perceived environmental costs, perceived economic benefits and perceived socio-cultural benefits) to determine which have a direct effect on the support for tourism development, and to determine moderator role of personal economic benefit in proposed relationships as well. Results suggest that personal economic benefit have important moderator role between community attachment and support for La Boqueria tourism development and also between community attachment and perceived sociocultural benefits and support for tourism development in general.
\end{abstract}

Keywords: resident attitudes, tourist attraction, food markets, host community, sustainability, Barcelona 
The viability of tourist destinations, especially urban cities, is a constant concern for societies in these times. Hence, local and national organizations act to attract more visitors, increase rates in their Gross Domestic Product (GDP) and climb the rankings in any list of top urban destinations. All these organizations aim to create and enhance a strong brand image for their cities. Therefore, the rivalry among them is intense, passionate, seeking for the best ideas, icons, and experiences. But, as many academics state, all this machinery needs the favorable support of host community as the cornerstone of tourism development (Gursoy \& Rutherford, 2004; Spencer \& Nsiah; 2013).

In this current context, food is an important attraction. Thus, food markets have a central role. Tourists who identify themselves as food market admirers are spending more time and money at these urban attractions. Consequently, day-by-day, these local icons increase their presence in tourist brochures, especially in urban areas (Pieniak et al., 2009, 101-102), as well as on general promotion website resources.

However, a food market visit is part of everyday life for any city's resident, both traditional residents, cosmopolitans, post-bohemians, immigrants, and adoptive citizens. They are commercial and social centers and places where the local culture and inhabitants' traditions are reflected. Therefore, they are one of the best examples of settings where people carry out their daily activities and shape their identity. Hence, tourists see food markets as a first-hand reflection of the cultures they want to discover, the native origin of any community (Hjalager \& Richards, 2002; Richards, 2012). In that sense, DMOs concentrate on exploiting this food market interest in their marketing proposals. Some of these initiatives are developed to rejuvenate, re-adapt and create interesting tourist attractions with the intention of benefiting 
both local hosts and guests, as Björk and Kauppinen-Räisänen (2014: 304) conclude regarding local food consumption. However, when tourist density inhibits the daily use of these public facilities, tension and conflict materialize. Thus, many scholars have interested in the analysis of the tourism impacts and their links with resident attitudes toward tourism support and rejection, but none has examined the effects of carrying capacity on food markets. It is therefore critical to understand the importance of these food centers for both types of users and to try to identify a compromise that would ensure its sustainability.

Looking for this necessary harmony and compatibility between tourists and host community, this study focus on community attachment, resident place image and socio-cultural, environmental and economic residents' perceptions in order to determine their relationship towards support for tourism development.

Accordingly, the aim of the study is threefold. First and central interest is to investigate factors that directly affect residents' assessment through tourism. Place image, community attachment, perceived socio-cultural benefits and perceived environmental costs are studied as independent variables. Support for La Boqueria tourism development and support for tourism development in general are considered dependent variables. Secondly, personal economic benefit is used as a moderating variable between independent and dependent variables. Thirdly, to provide insight to formulate governance policies related to the management of these tourist sites focusing on those aspects that generate a range of acceptance or rejection, designing compromises for its compatible use.

\section{LITERATURE REVIEW}


Food Markets Tourism

Any destination presents different stages of tourism development, according to Butler's Tourism Area Life Cycle (1980): exploration/discovery, consolidation; stagnation and, either rejuvenation or decline. In maturing and consolidated tourist places, DMOs focus their attention on new tourism resources, marketing programs and creative initiatives, attempting to engage more and more participants. Their aims base on optimizing opportunities and benefits and minimizing potential negative impacts. Therefore, in order to avoid the risk of stagnation and decline, city tourism organizations focus their efforts on rejuvenation, ensuring continuing relevance, updating and adding new attractions, mostly based on emotions and experiences. Also, these proposals imply citizenship into.

Gastronomic and culinary tourism are also included in this issue. The rise of gastronomic tourism has led to food markets appearing as a new type of resource and tool for the regeneration of urban centres (Dimitrovski \& Crespi-Vallbona, 2017). This area of tourism focuses its interest on the exploration and enjoyment of authentic meals and beverages as meanwhile they experience the local culture (Robinson \& Getz, 2016). Thus, this branch of tourism connects leisure, culture, and food (Smith \& Xiao, 2008) and provides travelers with memorable experiences (Hashimoto \& Telfer 2006; Okumus et al., 2013). Within this area "food-market lovers" appear as a new sub-category of food travelers: those tourists who enthusiastically spend a proportion of their holiday time visiting these urban establishments and seeking urban food market experiences (Crespi-Vallbona \& Dimitrovski, 2016: 853).

Depending on the effects that this contact with tourists has on host communities, food markets will be successful and sustainable or not. Positive effects have to be strengthened; 
negative ones, avoided or minimized. When benefits are perceived greater than costs, locals involve in the exchange, endorse future tourism development and feel committed with it (Jurowski et al., 1997; Gursoy et al., 2002; McGehee \& Andereck, 2004; Andereck et al., 2005; Oviedo-Garcia et al., 2008; Stylidis et al., 2014). Other studies consider the need to take into account other aspects in this host tourist's relation such as geographical and socioeconomic elements and the life cycle stage of the destination. Vargas-Sánchez et al. (2011: 462) recommend "contextualization of research, taking into account the local economic situation, the existing degree of tourism development of a particular area and tourist density".

Maturing and consolidated tourist destinations have the regular interference on residents' routine and habits. Therefore, they are exposed to a great dilemma: on one hand, providing satisfaction of tourist demands and, on the other, the preservation of their local identities. Thus, visitor interaction and disruption can have adverse effects on the quality of life of the host community. As Zhou et al. assert (2015: 31), the perception of these effects is "more subjective, emphasizing locals' feelings, which are intuitive, even irrational". As a result, personal benefits and costs are directly connected with the subjective feeling and judgment of one's own likes and dislikes (Ko \& Stewart, 2002).

Model of Support for Tourism Development

Residents' fear of losing their own spaces and identity show disagreement about the concentration and attraction of tourists (Vargas-Sánchez et al., 2011). They are also afraid of suffering accessibility problems, saturation of traffic, rubbish or noise, and, therefore they reveal their negative attitudes (Jurowski \& Gursoy, 2004). However, other studies present contrasting evidence. The attitude of those residents living closer to the tourism activity 
becomes more positive due to the favorable effects regarding personal income, jobs or tax revenues (Andereck et al., 2005; Nunkoo \& Ramkissoon, 2011). In short, research states a consistent finding: most people are aware of the decisive economic impact of tourism, even the detractor ones. However, host community tends to find mostly costs and damages with social, cultural and environmental changes.

In light of these statements, support for La Boqueria tourism development and tourism development in general is determined in accordance with following factors: place image, community attachment, perceived socio-cultural benefits, perceived environmental costs and personal economic benefits.

One relevant factor in understanding resident reaction towards tourism is place image or destination image. Place attachment is sort of consistent psychological attribute (Govers et al., 2007) whereas image shows a dynamic construct built upon the perceived place features, which may change and evolve with time, and people interaction (Stylidis et al., 2014). This perceived image and place attachment are the best way to obtain and preview residents' reaction towards perpetrated tourism changes. It is worth to highlight that place image has also to do with authenticity perception. Zhou et al. (2015:29) state that local residents are significantly concerned about culture commodification and loss of authenticity.

Community attachment relates to cognitive and affective ties among people in a specific place; that is, reasons which engage individuals in a community to remain, to be civically and politically committed with, and to feel a sense of connection and pertinence (Ainsworth and Bowlby, 1991). The studies suggest that the attachment to a community effects people's perception of tourism impact and their support (Jurowski et al., 1997; Um and Crompton 
1987). In that sense, Davis et al. (1988: 6) affirm that people who are natives are more positive about tourism than newcomers. Consequently, they provide a huge welcoming atmosphere to tourists.

Regarding perceived environmental costs there is evidence that host community with ecocentric attitudes (related to their perception of quality of life and wellbeing) affect significantly tourism impacts (Jurowski et al., 1997; Gursoy et al., 2002, 2004; Sirgy et al., 2010; Uysal et al., 2012; Jeon et al., 2016). So, concerning environmental costs, it is considered that the increasing tourism flow in the aisles of food markets can cause severe physical and environmental impacts such as building deterioration and degradation, vandalism, littering, dirt, pollution, pilferage, exceeding the infrastructures' carrying capacity, and noise.

Different scholars confirm positive significant correlation between perceived socio-cultural benefits and support for tourism development (Dyer et al., 2007; Gursoy et al., 2009; Prayag et al., 2013). The issue is that tourists increase the pride and the cultural identity to host community. Furthermore, it also creates opportunities for the conservation and revitalization of local traditions (Crespi-Vallbona \& Richards, 2007, 118). Furthermore, the interactions and conversations between individuals are facilitated in food markets. Also, it provides contact with unfamiliar environments, and the acceptance of different cultures and costumes (Berno \& Ward, 2005: 595).

Finally, attention should be given to personal economic benefits. In general, host community feels that tourism reduces unemployment by creating new jobs, and providing businesses and investment opportunities. They also consider the reinforcement in the whole 
economy due to its multiplier effects (Ko \& Stewart, 2002). Therefore, communities more economically dependent on tourism are generally more positive and supportive about tourism development (McGehee \& Andereck, 2004; Andereck et al., 2005; Frauman \& Banks, 2011; Látková \& Vogt, 2012; Zhou et al., 2015).

The personal economic benefits are recognized as an important antecedent of support for tourism development due to the generated employment (Ko \& Stewart, 2002; Jurowski \& Gursoy, 2004; Oviedo-Garcia et al., 2008; Zhou et al., 2015). In that sense, personal economic benefits could act as a moderation variable that changes the relationship between independent and dependent variables.

\section{EMPIRICAL ANALYSIS}

Research model of four independent variables (resident place image, community attachment, perceived socio-cultural benefits and perceived environmental costs), personal economic benefits as a moderator variable, and dependent variables (support for La Boqueria tourism development and support for tourism development in general) is shown in Figure 1. The model is designed to determine the statistically significant drivers for tourism development support, both in La Boqueria and in Barcelona, but also to test the moderator role of personal economic benefits between independent and dependent variables.

Figure 1. Proposed research model 


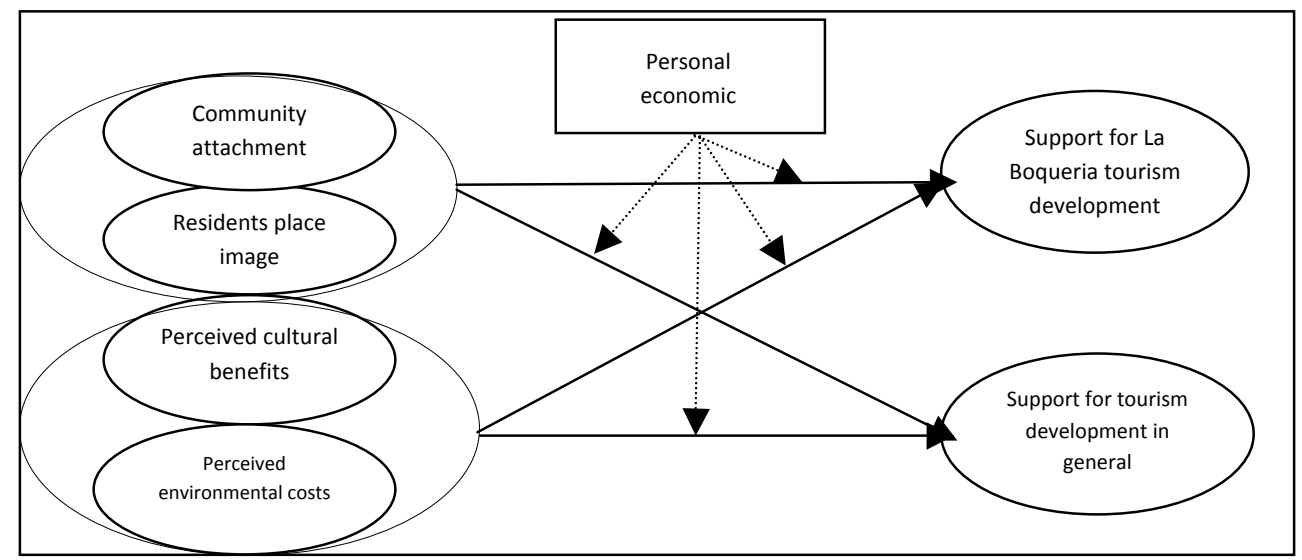

METHODOLOGY

Barcelona is a mature, highly rated, city destination involved in attracting visitors by offering new products, symbols and emotional experiences (Duro and Rodriguez, 2015: 531).

Previously, tourism in Barcelona was a complementary activity, but nowadays it has become a structural component of its production system, and part of everyday life for Barcelona's inhabitants. La Boqueria Food Market highlights as a "must-see" for tourists when visiting Barcelona.

One inherent effect is the emerging conflict between the market's use as a public service for residents (consumers, everyday local buyers) and attraction spot for tourists. This phenomenon in the food market is similar to other experiences across the city. Pressure points created by tourism such as congestion, high volumes of people walking around the alleys, picture-taking, eating in bars and restaurants, socializing on the corners and small squares and buying ready-made food, fruit juices, etc., create friction and at times, tense situations between both user groups of the market. Consequently, the negative regard of Barcelona's population towards tourism increases daily. 
The research is conducted on a convenience sample of 200 respondents: local residents visiting La Boqueria. The survey took place from the beginning of March 2015 until the end of June 2015, between the hours of 9:00 and 17:00, the usual time for shopping by regular users in the market. Responders expressed their level of agreement with 18 questions grouped around eight latent variables. Questionnaire was pretested to verify that questions were clear and comprehensible. Then, a preliminary survey was performed on a small group of 30 randomly selected respondents. From the analysis of comments and suggestions obtained from the pilot sample, changes were made in order to shape the final version of the questionnaire. Finally, there were 34 questionnaires rejected.

The statements and model latent variables were selected based on relevant literature as it follows. Two items based on Stylidis et al. study (2014) and adjusted for the purposes of the study were used to measure residents place image. Community attachment was measured via the use of six adopted and adapted items from several studies (Gursoy et al., 2009; Lee, 2013). Perceived environmental costs were measured via two items based on two pieces of research (Gursoy et al., 2009; Nunkoo \& Ramkissoon, 2011). The questions related to perceived socio-cultural benefits also consisted of two items (Lee, 2013), which were also adjusted for the purposes of the research. Personal economic benefits, as the moderation variable, consisted of two items taken and adapted from the research of Oviedo-Garcia et al. (2008). Support for La Boqueria tourism development as a dependent variable was measured via two items extracted from literature review focusing on resident attitudes (Oviedo-Garcia et al., 2008; Lee, 2013), while support for tourism development in general was represented with two items from the study of Oviedo-Garcia et al. (2008). 
Selected statistical analyses were implemented in SPSS and AMOS: reliability analysis, confirmative factor analysis and hierarchical regression moderation. In the first step, based on the value of Cronbach's alpha coefficient, the reliability of the items in latent variable was estimated. Then, confirmative factor analysis is implemented in order to test the fit of the research model. Later on, main and interaction effects of both dependent variables were tested through the use of hierarchical moderated regression analysis. In addition, independent variables were centered and multiplied by each other, to avoid a multicollinearity problem that may occur when calculating interaction effects.

\section{RESULTS}

The sample consisted of $47.5 \%(95)$ male respondents and $52.5 \%(105)$ female respondents. The largest proportion of respondents was for group 45-54 (25\%), while the other age groups were normally distributed. With regards to marital status, married respondents accounted for $44 \%$ (88); single accounted for $34 \%$ (68) and divorced or widowed had a share of $22 \%$ (44) of the sample. With regards to level of education, $28.5 \%$ of respondents were currently studying for a master degree, $26 \%$ possessed a high school diploma, $20.5 \%$ of respondents had a bachelor's degree, $14.5 \%$ of respondents had a master degree and $10.5 \%$ an associate degree. The sample included those mainly employed by the private sector $30.5 \%(61)$, as well as $24.5 \%$ from the public sector, unemployed $17.5 \%$, retired $13 \%$, housewives $7.5 \%$ and other $7 \%$.

Table 1. Sample sociademographic characteristics $(n=200)$

\begin{tabular}{|l|l|}
\hline Gender & Number of respondents $(\%)$ \\
\hline Male & $95(47.5 \%)$ \\
\hline Female & $105(52.5 \%)$ \\
\hline Age & \\
\hline $18-24$ & $33(16.5 \%)$ \\
\hline
\end{tabular}




\begin{tabular}{|l|l|}
\hline $25-34$ & $33(16.5 \%)$ \\
\hline $35-44$ & $34(17.0 \%)$ \\
\hline $45-54$ & $50(25.0 \%)$ \\
\hline $55-64$ & $24(12.0 \%)$ \\
\hline$>65$ & $26(13.0 \%)$ \\
\hline Marital status & \\
\hline Married & $88(44.0 \%)$ \\
\hline Single & $68(34.0 \%)$ \\
\hline Other & $44(22.0 \%)$ \\
\hline Education & \\
\hline High school graduate & $52(26.0 \%)$ \\
\hline Associate degree & $21(10.5 \%)$ \\
\hline Bachelor's degree & $41(20.5 \%)$ \\
\hline Master studies & $57(28.5 \%)$ \\
\hline Master's degree & $29(14.5 \%)$ \\
\hline Employment & \\
\hline Employee at public service & $49(24.5 \%)$ \\
\hline Employee at private sector & $61(30.5 \%)$ \\
\hline Non employed & $35(17.5 \%)$ \\
\hline Housewife & $15(7.5 \%)$ \\
\hline Retired & $26(13.0 \%)$ \\
\hline Other & $14(7.0 \%)$ \\
\hline
\end{tabular}

At the beginning of the statistical analysis the approach to item total correlation was applied with the aim to reduce the initial number of items used. Based on these results, it was decided that two statements should be removed, one from perceived costs and another from perceived benefits. After the exclusion of these two items, a reliability analysis was conducted and a confirmatory factor analysis was performed. The values of Cronbach's alpha coefficient are shown in Table 2. Variables level of reliability measured with Cronbach's alpha coefficient is over the required threshold of 0.6 (Hair, et al., 2006).

Table 2. Reliability analysis of proposed research model (Cronbach's alpha)

\begin{tabular}{|l|l|}
\hline Variables & Cronbach's alpha \\
\hline Residents place image & 0.673 \\
\hline Community attachment & 0.931 \\
\hline Perceived benefits & 0.757 \\
\hline Perceived costs & 0.773 \\
\hline Personal economic benefits & 0.814 \\
\hline Support for La Boqueria tourism development & 0.725 \\
\hline Support for tourism development in general & 0.792 \\
\hline
\end{tabular}


The fit testing of the proposed model shows that value of $\chi^{2} / \mathrm{df}$ is lower than the threshold of 3 (Bagozzi and Yi, 1988). Also, other fit indicies (CFI Index $=0.958$; The TLI = 0.949; IFI = 0.959) have values greater than 0.9 (Byrne, 1998), while the value of the RMSEA (RMSEA = 0.047) coefficient is lower than the threshold of 0.1 (Steiger, 1990). The results of the study meet these requirements (Table 3).

Table 3 shows the adequacy results of the final statements used. All confirmatory factor loadings were greater than 0.6 . The proposed model also delivers an acceptable level of convergent and discriminatory validity and composite reliability. The model has composite reliability (CR), due to the fact that the CR values of all variables are over the threshold of 0.6 (Bagozzi \& Yi, 1988). The average variance extracted (AVE) of all the variables is greater than 0.5 (Table 3).

Table 3. Results of confirmatory factor analysis

\begin{tabular}{|l|c|}
\hline Constructs and items (AVE and CR) & Loading \\
\hline Residents place image (0.510; 0.675) & \\
\hline It is clean & 0.747 \\
\hline It is safe & 0.679 \\
\hline Community attachment (0.697; 0.932) & 0.691 \\
\hline I enjoy living in this community more than other communities & 0.884 \\
\hline I feel that this community is a part of me & 0.897 \\
\hline Living in this community says a lot about who I am & 0.912 \\
\hline Living in this community means a lot to me & 0.853 \\
\hline I am very attached to this community & 0.749 \\
\hline I feel a strong sense of belonging to this community & \\
\hline Perceived socio-cultural benefits (0.612; 0.759) & 0.753 \\
\hline The market offers me the opportunity to meet people from other cultures & 0.811 \\
\hline The market offers me the opportunity to meet local people & \\
\hline Perceived environmental costs (0.638; 0.778) & 0.846 \\
\hline Tourism in La Boqueria increase noise levels & 0.748 \\
\hline Tourism in La Boqueria increase more pollution & \\
\hline Personal economic benefits (0.700;0.822) & 0.752 \\
\hline The tourism development of my community positively affects to my professional activity & 0.913 \\
\hline In general, I perceive that tourism in my community has personally benefit me & \\
\hline Support for La Boqueria tourism development (0.581;0.733) & 0.836 \\
\hline I support the development of La Boqueria tourism initiatives & 0.681 \\
\hline Tourism must be developed focusing on attractions, such as food market La Boqueria & 0.796 \\
\hline Support for tourism development in general (0.657; 0.793) & 0.825 \\
\hline Tourism industry will continue to play an important economic role in my community & \\
\hline Tourism can be one of the most important industries for a community & \\
\hline
\end{tabular}


Notes: $\chi^{2}=159.909 ; \mathrm{df}=113 ; \mathrm{p}=0.03 ; \chi^{2} / \mathrm{df}=1.415 ; \mathrm{GFI}=0.921 ; \mathrm{CFI}=0.975 ; \mathrm{TLI}=0.966 ; \mathrm{IFI}=0.975$; RMSEA $=0.045$.

Hierarchical moderated regression in four steps was applied in order to check main interaction effects. Firstly, the calculation of the main effects of independent variables on the dependent variable (support for La Boqueria tourism development) was performed (Model 1). In the second step, personal economic benefits were included in the model as a moderator. Interaction effects were calculated with regards to support for La Boqueria tourism development (Model 2). In the third step, the influence of independent variables on support for tourism development in general, was examined (Model 3). In the fourth step, interaction effects were calculated to determine the impact of personal economic benefits on support for tourism development in general (Model 4). Since all VIF values were lower than 5, multicollinearity was not an issue within the study.

Table 4. Results of hierarchical moderated regression analysis (dependent variables: support for La Boqueria tourism development)

\begin{tabular}{|c|c|c|}
\hline & Model 1 & Model 2 \\
\hline \multicolumn{3}{|l|}{ Independent variables } \\
\hline Residents place image & $0.085^{\mathrm{ns}}$ & $0.045^{\mathrm{ns}}$ \\
\hline Community attachment & $-0.110^{*}$ & $-0.093^{\mathrm{ns}}$ \\
\hline Perceived environmental costs & $-0.107^{*}$ & $-0.075^{\mathrm{ns}}$ \\
\hline Perceived socio-cultural benefits & $0.339^{* * *}$ & $0.376^{* * *}$ \\
\hline Personal economic benefits & $0.286^{* * *}$ & $0.262^{* * *}$ \\
\hline \multicolumn{3}{|l|}{ Interaction } \\
\hline Residents place image * Personal economic benefits & & $0.021^{\mathrm{ns}}$ \\
\hline Community attachment $*$ Personal economic benefits & & $0.177^{* *}$ \\
\hline Perceived environmental costs * Personal economic benefits & & $0.097^{\mathrm{ns}}$ \\
\hline $\begin{array}{l}\text { Perceived socio-cultural benefits } * \text { Personal economic } \\
\text { benefits }\end{array}$ & & $0.069^{\mathrm{ns}}$ \\
\hline $\mathrm{R}^{2}$ & 0.293 & 0.340 \\
\hline Adjusted $\mathrm{R}^{2}$ & 0.275 & 0.308 \\
\hline
\end{tabular}

Note: Standardized regression coefficients are reported in columns marked Model 1, Model 2; ${ }^{* * *} \mathrm{p}<0.01 ;{ }^{* *} \mathrm{p}<0.05 ;{ }^{*} \mathrm{p}<0.1 ;{ }^{\text {ns }}-$ not significant

The results of the analysis of the main effects suggested that perceived socio-cultural benefits, personal economic benefits, community attachment and perceived environmental 
costs had significant impact on support for La Boqueria tourism development. Among these four variables, perceived socio-cultural benefits have the greatest impact on support for La Boqueria tourism development. Research results did not confirm a significant effect on support for La Boqueria tourism development due to resident place image (Table 4).

Secondly, variable personal economic benefit as moderator was used with aim to calculate the interaction effects. Only the interaction effect between community attachment and personal economic benefits was statistically significant (Table 4).

Table 5. Results of hierarchical moderated regression analysis (dependent variables: support for tourism development in general)

\begin{tabular}{|l|l|l|}
\hline & Model 3 & Model 4 \\
\hline Independent variables & & \\
\hline Residents place image & $0.021^{\mathrm{ns}}$ & $-0.010^{\mathrm{ns}}$ \\
\hline Community attachment & $-0.186^{* *}$ & $-0.195^{* *}$ \\
\hline Perceived environmental costs & $-0.088^{\mathrm{ns}}$ & $-0.071^{\mathrm{ns}}$ \\
\hline Perceived socio-cultural benefits & $0.181^{* *}$ & $0.218^{* *}$ \\
\hline Personal economic benefits & $0.391^{* * *}$ & $0.364^{* * *}$ \\
\hline Interaction & & \\
\hline Residents place image * Personal economic benefits & & $0.104^{\mathrm{ns}}$ \\
\hline Community attachment * Personal economic benefits & & $0.145^{* *}$ \\
\hline Perceived environmental costs Personal economic benefits $^{\mathrm{ns}}$ & & $0.010^{\mathrm{ns}}$ \\
\hline $\begin{array}{l}\text { Perceived socio-cultural benefits * Personal economic } \\
\text { benefits }\end{array}$ & & $0.124^{*}$ \\
\hline $\mathrm{R}^{2}$ & 0.242 & 0.300 \\
\hline Adjusted $^{2}$ & 0.222 & 0.267 \\
\hline
\end{tabular}

Note: Standardized regression coefficients are reported in columns marked Model 3, Model 4; $\mathrm{p}<0.01 ;{ }^{* *} \mathrm{p}<0.05 ;^{*} \mathrm{p}<0.1 ;{ }^{\text {ns }}-$ not significant

In the third step, the analysis of the main effects indicated that personal economic benefits, perceived socio-cultural benefits, and community attachment had significant impact on support for tourism development in general. Among these three variables, personal economic benefits had the greatest impact on support for tourism development in general. Perceived socio-cultural and personal economic benefits had a positive significant impact on the level 
of support for tourism development in general. While community attachment was statistically significant, it was in a negative manner (Table 5).

Finally, the interaction effects between independent variables and dependent variable (support for tourism development in general) were calculated. In this step, personal economic benefit was again set as a moderating variable. As the results suggest, the interaction effect between community attachment and perceived socio-cultural benefits is statistically significant (Table 5).

\section{DISSCUSION AND IMPLICATIONS}

Theoretical Implications

Achieving community support necessary for tourism development is a rather complex process. Tourism development depends on several factors, either the current phase in the destination life cycle or the modality of tourism. The research was focused on one tourist attraction as part of Barcelona (Spain), a mature tourism destination: La Boqueria Food Market. Food markets as tourist attractions offer a wide range of benefits to visitors: local food consumption, interaction with the local population and native producers, and the pursuit of authentic heritage and culture. Local community is essential part of these unique experiences, since attitudes of the locals towards community-based tourism development is decisive for the overall impression of tourists. Therefore, the interaction of host residents and tourists is beneficial in the long-term for both parties. 
This study enhances the theoretical background by explaining how local community members react towards tourism development in urban food markets. The originality of the study lies in the confirmed validity of the model, in reference to the recognition of the importance of moderator role of personal economic benefits, providing evidence of costbenefit hosts' perceptions. Also provides significance of personal economic benefits for tourism development as it has been recognized in earlier studies. Thus, our results also confirm conclusions of other several recent studies: if local community members personally benefit from tourism development they have more favorable attitudes towards its development.

To demonstrate the validity of the model of local community support for tourism development in La Boqueria food market, research was divided into four phases. In the first stage, the following variables have been assessed: the importance of the effect of community attachment, resident place image, socio-cultural and economic perceived benefits, and environmental perceived costs, on support for La Boqueria tourism development. Obtained results confirmed previous conclusions about the positive significant correlation between socio-cultural benefits and support for tourism development (Dyer et al., 2007; Gursoy et al., 2009; Prayag et al., 2013), and between personal economic benefits and support for tourism development (Ko \& Stewart, 2002). Earlier studies suggest that if local residents have reasonably doubts that tourism may damage the environment they will be opposed to development (Hillery et al., 2001; Oviedo-Garcia et al., 2008), while Prayag et al. (2013) in his study found a negative, but non-significant link between environmental costs and support for tourism development. Several studies were also unable to find linkage between community attachment and support for tourism development (Gursoy et al., 2002; Choi \& Murray, 2010; Lee, 2013). Harrill (2004) stated that locals more attached to their community 
have pronounced hostile attitude towards tourism development in general, as tourism negatively influences quality of life.

Therefore, in summary, the perception of socio-cultural benefits and personal economic benefits by local residents positively influence support level of La Boqueria tourism development. Yet, perceived environmental costs and community attachment are obstacles, as conveyed by their negative values, in the process of securing host resident support for La Boqueria tourism development, while their perception of La Boqueria image does not have an important role in the community support construct.

In the second step, personal economic benefits were set as moderating variable between independent variables and one of the dependent variable. In general, local communities which are more economically dependent on tourism encourage tourism development more vehemently, with a higher probability of being supportive of further tourism development. Similarly to this study, Oviedo-Garcia et al. (2008) examined whether there were significant differences between residents concerning personal economic benefits from tourism. Personal economic benefits were found significantly related to positive perceptions of tourism and consequently, support for tourism development.

It can be concluded that personal economic benefits alter the impact degree of community attachment on support for La Boqueria tourism development. Therefore, if residents have some personal economic benefits from tourism, their level of support for La Boqueria tourism initiatives increase, together with community attachment. Similar findings were found in Látková and Vogt's study (2012), confirming that local residents strong sense of community affiliation influence higher level of acceptance of tourism development. 
The third model depicts the relation between independent variables and a dependent variable, so the focus of the dependent variable is redirected from support for La Boqueria as a tourist attraction to the host resident perception of tourism development in general.

Finally, in the fourth stage, personal economic benefits are observed as a moderating variable in relation to independent variables and dependent. It can be concluded that personal economic benefits strengthen positive relationship between community attachment and support for tourism development in general, meaning if local residents gain personal benefits, their support for tourism development will rise as they are more community attached. This relationship changes drastically when it is compared to direct effects, since the relationship without a moderation role of personal economic benefits is negative. Thus, when tourism development guarantees personal economic benefits for host community members, it contributes to ensuring their support for tourism initiatives in general, which had been previously confirmed in Nicholas et al. study (2009). Also, personal economic benefits increase the impact of perceived socio-cultural benefits on support for tourism development. This indicates that when local residents perceive that they gain personal economic benefits, their perception of a positive link between socio-cultural benefits and their level of support for tourism development in general, is assured. If economic benefits are distributed equally within a community, the positive perception of socio-cultural benefits will increase the support for tourism development in general.

\section{Managerial Implications}


The conducted research offers useful guidelines for policy planners, both organizations and individuals interested in tourism development and its sustainability, mainly those who manage La Boqueria food market. Support for tourism development is dependent on the perception of benefits and costs, and the perception that the benefits for the host community outweigh possible costs. Food markets could be seen as powerful tool for local employment, entrepreneurship and urban regeneration, so local residents need to be more included in its activities, planning and governance. Providing residents with comprehensive information regarding possible benefits and costs which may arise from tourism development will allow them to participate and have more control over this industry (Nunkoo \& Ramkinsson, 2011).

Food market management needs to be more involved in the organization of spent time and used space by tourists in order to reconcile confronting interests of tourists and host residents on the daily basis. Since food market visits are an everyday routine for inhabitants as well as for tourists, the main and key issue is the food market sustainability, in order to maintain the balance between tourists and traditional customers and find a compromise among all of them. On the contrary, the food marked risks to become a turistified hall, without any local interest, just a take-away food market just useful for tourists.

Certainly, personal economic benefits are a focal point for obtaining community support for tourism development. Thus, if tourism development brings personal benefits to residents, those residents will perceive the favorable effects of tourism in a stronger manner than they do the unfavorable effects. Informing community members about potential personal economic benefits could help in providing support for tourism initiatives. An individual approach is highly recommended, with the forming of focus groups to alleviate any concerns, 
but also to encourage leadership and entrepreneurship, giving them chance to become economically independent.

Highly place-attached residents are quite relevant for tourism development support, since their attitudes, as the results suggest, are negative towards current tourism initiatives. Food markets figure as social glue, fostering the community ties and building community cohesion. Thus, involving community-attached residents in any kind of tourist activities, especially if it guarantees some income, will positively influence long-term support of them. Also, resident involvement in the planning process could enhance the perception that they are actually part of tourism development in a justifiable way, from their own perspective (Sirgy et al., 2010; Jeon et al., 2016).

To avoid the open hostility between tourists and residents due to the day to day usage of food markets, managers shall regulate and limit the use and interest of this public space. First of all, visits by organized groups of tourists have to be restricted during the most common purchasing time of residents (that is during Fridays, all the day, and Saturdays from opening time to 15:00). Secondly, stalls cannot sell goods only and exclusively for tourists. They should combine goods for the two focused customers, thinking first about residents.

In this specific case, the management of La Boqueria food market needs to become aware of and direct its efforts to readapt services of food market in a balanced and sustainable way. Balancing tourism pressure between weekends and working days is only confident path towards sustainable growth. Crowding isn't only a resident problem, since more and more tourists will be turned down by overcrowding, so it will become a huge problem for its management. La Boqueria popularity can fade, as tourists demand unique cultural heritage 
and authentic gastronomic experience. Then, the tourist attention can be redirected towards smaller and less famous food markets, avoiding the turistified Boqueria.

Future research and limitations

It is also important to highlight a number of limitations within the research. The model is not sufficiently comprehensive, as it could include other variables that better describe community attitudes, such as community involvement. Perceived benefits and costs could be addressed separately for every category (socio-cultural, economic and environmental) and also differentiating vendors and food market users. The implementation of cluster analysis would be highly desirable, in order to profile groups with similar attitudes, so their needs and concerns could be addressed more easily within the future planning process. Sample size is one more limitation of the study, but as food markets have not been previously explored in this manner, the research and its sample size could act a satisfactory starting point (as a pilot study) for additional quantitative studies.

Seasonal phenomena in the market influence the change in perception of local residents regarding their quality of life and well-being, especially during the days with more visits. Therefore, a longitudinal study should be done in the future, comparing low and high tourism influx moments.

\section{REFERENCES}

Ainsworth, M. D. S., \& Bowlby, J. (1991). An ethological approach to personality development. American Psychologist, 46, 331-341. 
Andereck, K. L., Valentine, K. M., Knopf, R. C., \& Vogt, C. A. (2005). Residents' perceptions of community tourism impacts. Annals of Tourism Research, 32(4), 1056-1076. Bagozzi, R. R., \& Yi, Y. (1988). On the evaluation of structural models. Journal of the Academy of Marketing Science, 16, 74-94.

Berno, T., \& Ward, C. (2005). Innocence abroad a pocket guide to psychological research on tourism. American Psychologist, 60, 593-600.

Björk, P., \& Kauppinne-Räisänen, H. (2014). Exploring the multi-dimensionality of travellers'culinary-gastronomic experiences. Current Issues in Tourism, 1-21 https://doi.org/10.1080/13683500.2013.868412.

Butler, R. W. (1980). The concept of a tourist area cycle of evolution: implications for management of resources. The Canadian Geographer/Le Géographe Canadien, 24(1), 5-12. Byrne, B. M. (1998). Structural equation modelling with LISREL, PRELIS, and SIMPLIS: Basic concepts, applications, and programming. Mahwah, NJ: Lawrence Erlbaum. Crespi-Vallbona, M., \& Dimitrovski, D. (2016). Food markets visitors: a typology proposal. British Food Journal, 118(4), 840-857.

Crespi-Vallbona, M., \& Richards, G. (2007). The meaning of cultural festivals: stakeholder perspectives in Catalunya. International Journal of Cultural Policy, 13(1), 103-122.

Davis, D., Allen, J., \& Cosenza, R. (1988). Segmenting local residents by their attitudes, interests, and opinions. Journal of Travel Research, 27, 2-8.

Dimitrovski, D., \& Crespi-Vallbona, M. (2017). Role of food neophilia in food market tourists' motivational construct: The case of La Boqueria in Barcelona, Spain. Journal of Travel \& Tourism Marketing, doi: 10.1080/10548408.2016.1193100.

Duro, J. A., \& Rodríguez, D. (2015). Barcelona como municipio turístico: Algunos datos evolutivos y elementos de futuro. Documents d'Anàlisi Geogràfica, 61(3), 507-538. 
Dyer, P., Gursoy, D., Sharma, B., \& Carter, J. (2007). Structural modeling of resident perceptions of tourism and as sociated development on the Sunshine Coast, Australia. Tourism Management, 28, 409-422.

Frauman, E., \& Banks, S. (2011). Gateway community resident perceptions of tourism development: Incorporating importance-performance analysis into a limits of acceptable change framework. Tourism Management, 32(1), 128-140.

Govers, R., Go, F. M., \& Kumar., K. (2007). Promoting tourism destination image. Journal of Travel Research, 46(1), 15-23.

Gursoy, D., Chi, C. G., \& Dyer, P. (2009). An examination of locals' attitudes. Annals of Tourism Research, 36, 723-726.

Gursoy, D., \& Rutherford, D. (2004). Host attitudes toward tourism: An improved structural model. Annals of Tourism Research, 31(3), 495-516.

Gursoy, D., Jurowski, C., \& Uysal, M. (2002). Resident attitudes a structural modeling approach. Annals of Tourism Research, 29(1), 79-105.

Hair, J. F., Black, W. C., Babin, B. J., Anderson, R. E., \& Tatham, R. L. (2006). Multivariate data analysis (6th ed.). Upper Saddle River, NJ: Prentice-Hall.

Hjalager, A. M. (2002). A typology of gastronomy tourism. In A. M. Hjalager \& G. Richards (Eds) Tourism and Gastronomy (pp. 21-35). London, UK: Routledge.

Harrill, R. (2004). Residents' attitudes toward tourism development: A literature review with implications for tourism planning. Journal of Planning Literature, 18(3), 251-266.

Hashimoto, A., \& Telfer, D. J. (2006). Selling Canadian culinary tourism: Branding the global and the regional product. Tourism Geographies, 8(1), 31-55.

Hillery, M., Nancarrow, B., Griffin, G., \& Syme, G. (2001). Tourist perception of environmental impact. Annals of Tourism Research, 28, 853-867. 
Jeon, M. M., Kang, M. M., \& Desmarais, E. (2016). Residents' perceived quality of life in a cultural-heritage tourism destination. Applied Research Quality Life, 11, 105-123.

Jurowski, C., Uysal, M., \& Williams, R. (1997). A theoretical analysis of host community resident reactions to tourism. Journal of Travel Research, 36(2), 3-11.

Jurowski, C., \& Gursoy, D. (2004). Distance effects on residents' attitudes toward tourism. Annals of Tourism Research, 31(2), 296-312.

Ko, D. W., \& Stewart, W. P. (2002). A structural equation model of residents' attitudes for tourism development. Tourism Management, 23(5), 521-530.

Látková, P., \& Vogt, C. A. (2012). Residents' attitudes toward existing and future tourism development in rural communities. Journal of Travel Research, 51(1), 50-67.

Lee, T. H. (2013). Influence analysis of community resident support for sustainable tourism development. Tourism Management, 34, 37-46.

McGehee, N. G., \& Andereck, K. L. (2004). Factors predicting rural residents' support of tourism. Journal of Travel Research, 43(2), 131-140.

Nicholas, L., Thapa, B., \& Ko, Y. (2009). Residents' perspectives of a World heritage site the Pitons Management Area, St. Lucia. Annals of Tourism Research, 36(3), 390-412.

Nunkoo, R., \& Ramkissoon, H. (2011). Developing a community support model for tourism. Annals of Tourism Research, 38(3), 964-988.

Okumus, F., Kock, G., Scantlebury, G., \& Okumus, B. (2013). Using local cuisines when promoting small Caribbean Island destinations. Journal of Travel and Tourism Marketing, $30(4), 410-429$.

Oviedo-García, M. A., Castellano-Verdugo, M., \& Martín-Ruiz, D. (2008). Gaining residents' support for tourism and planning. International Journal of Tourism Research, 10(2), 95-109. 
Pieniak, Z., Verbeke, W., Vanhonacker, F., Guerrero, L., \& Hersleth, M. (2009).

Associations between traditional food consumption and motives for food choice in six European countries. Appetite, 53(1), 101-108.

Prayag, G., Hosany, S., Nunkoo, R., \& Alders, T. (2013). London residents' support for the 2012 Olympic Games: The mediating effect of overall attitude. Tourism Management, 36, $629-640$.

Robinson, R. N., \& Getz, D. (2016). Food enthusiasts and tourism: Exploring food involvement dimensions. Journal of Hospitality \& Tourism Research, 40(4), 432-455. Sirgy, M. J., Widgery, R. N., Lee, D. J., \& Yu, G. B. (2010). Developing a measure of community well-being based on perceptions of impact in various life domains. Social Indicators Research, 96, 295-311.

Smith, S., \& Xiao, H. (2008). Culinary tourism supply chains: a preliminary examination. Journal of Travel Research, 46, 289-299.

Spencer, D. M., \& Nsiah, C. (2013). The economic consequences of community support for tourism: A case study of a heritage fish hatchery. Tourism Management, 34, 221-230.

Steiger, J. H. (1990). Structural model evaluation and modification: An interval estimation approach. Multivariate Behavioral Research, 25(2), 173-180.

Stylidis, D., Biran, A., Sit, J., Szivas, E. (2014). Residents' support for tourism development: The roles of residents' place image and perceived tourism impacts. Tourism Management, 45, $260-274$.

Uysal, M., Perdue, R., \& Sirgy, R. (2012). Handbook of tourism and quality-of-life research: enhancing the lives of tourists and residents of host communities. Dordrecht, Netherlands: Springer. 
Vargas-Sánchez, A., Porras-Bueno, N., \& Plaza-Mejia, M. (2011). Explaining residents' attitudes to tourism: Is a universal model possible? Annals of Tourism Research, 38(2), 460480.

Zhou, Q., Zhang, J., Zhang, H., \& Ma, J. (2015). A Structural model of host authenticity. Annals of Tourism Research, 55, 28-45. 